\title{
Cellulose Fibres Used in Building Materials
}

\author{
Nadezda Stevulova ${ }^{1}$, Viola Hospodarova ${ }^{2}$, \\ ${ }^{1,2}$ Technical University of Kosice
}

\begin{abstract}
The paper presents application of cellulose fibres in a pulp form from waste paper to mortar or plaster. The pulp from waste paper substitutes a part of inorganic filler or binder in cementitious composites. The characterization of properties and use of mortar or plaster mixtures as well as wood pulp fibres used in cement-based materials is presented in the article. The results of testing the technically important parameters (density, water resistance, coefficient of thermal conductivity, tensile strength at bending) of composites which were obtained by compiling the available works are summarized.
\end{abstract}

Keywords - Cellulose fibres, dry plaster mixtures, pulp, recycled paper, composite.

\section{INTRODUCTION}

Nowadays, material recycling is a growing trend in the development of building materials and further usage of secondary raw materials for production of new building materials. We also have noted the transition from the application of non-renewable sources of raw materials to renewable raw materials. Renewable raw materials include organic sources of raw materials which are based on plant fibres (hemp hurds, sisal, coir, wood pulp) and recycled materials such as waste paper. This material is used to contribute to environmental protection and to save nonrenewable resources of raw materials.

Large quantities of lignocellulosic waste are being generated worldwide. Lignocellulosic materials are obtained from wood and natural plants. They are composed of lignin and cellulosic compounds as the main chemical constituents. Agriculture and construction are just two examples of the many sources of waste. This accumulation of waste leads to serious environmental concerns [1]. Karade's research [2] has found that the use of waste and natural cellulose fibres as reinforcement in cement composites has enormous potential in the field of recycled materials for building construction.

In fact, lignocellulosic fibres or particles are available mainly from wood, but several local annual plants and agricultural crops as well as industrial residues can also be considered as potential sources of raw materials. The increasing demand for lignocellulosic materials for traditional uses (mainly paper and textile production, but also for cellulose derivatives) and their potential incorporation into new material families necessitates looking for new sources. For this purpose, several studies have tried to valorise various agricultural or industrial by-products available locally [3].

Wood pulp fibres are unique reinforcing materials that offer numerous advantages. They are non-hazardous, renewable, and readily available at relatively low cost compared to other commercially available fibres. As a result, pulp fibre-cement composites have found practical applications in the recent decades in the commercial market as a replacement for hazardous asbestos fibres. Today, pulp fibre-cement composites can be found in products such as extruded nonpressure pipes and non-structural building materials [4].

Paper is an example of a valuable material that can be recycled. Disposable paper available in abundance throughout the world is composed mainly of short natural cellulose fibres and is already used in many local low materials. Waste paper comes from various sources such as newspapers, office and printing papers and boxes. Each has a different type of fibre quality, and mixing all these papers of different qualities will reduce the purity of the highest quality fibre. The quality of the waste determines the end quality of the recycled paper. Therefore, an investigation concerning the potential of different re-pulped waste paper types as construction materials is essential in order to gain an insight into their behaviour and properties [1].

One of the types of building products based on the use of cellulosic material is mortar. Mortars, including rendering mortar and plastering mortar, are used for ages and play an important role in shaping the surface structures. Mortars are used to cover the wall and ceiling surfaces. These finish materials are used as a design element or as protection of masonry against weather influence and mechanical loads. Rendering and plastering mortar must comply with the standards and requirements [5].

The aim of this review is to compile the available literature data on the use of cellulosic fibres, mainly fibres from the recycled paper. It can be used as a guideline for our upcoming research of utilization of cellulosic fibres derived from recycled paper into mortar/plaster.

\section{MORTAR AND ITS CHARACTERIZATIONS}

Mortar is a construction material prepared mixing small aggregates, inorganic binder, appropriate additives and admixtures. Resulting granular mixture is stirred with water to the desired consistency [6].

The properties and characteristics of the mortars mainly depend on the nature of the binder component such as lime, gypsum, cement. That is the reason why its evolution has been closely related to the development of artificial cementitious materials [7].

\section{A. History of mortars}

The first binder was used in surface treatment of clay, which when mixed with water creates well spreadable material. Later the Egyptians burned gypsum in open fires, crushed to a powder and mixed with water, thus they prepared mortar for big buildings - pyramids. In very early Greek and 
Roman architecture lime was used as stucco and it was airy binder. By the 18th century, hydraulic binders began to partially replace lime. These new materials hardened more quickly and developed higher mechanical strengths. In the 19 th century, the invention of Portland cement (in 1824 by a British mason named Joseph Aspdin) revolutionized the world of building materials, completely displacing the use of lime in all types of civil and military constructions. Portland cement is a commodity and primary building product in the world and it soon became the cement of choice for exterior plaster due to its strength and durability [5], [7].

The use of fibres as reinforcement is as old as human civilization. Traces of natural fibres such as flax, cotton, silk, wool and plant fibres have been located in the constructions of ancient civilizations all over the globe. For example, the recorded usage of flax can be dated back to $5000 \mathrm{BC}$; it is considered the oldest natural fibre [8].

\section{B. General information and composition of mortar}

Mortar can be prepared:

- from starting materials at construction site;

- by a factory as a dry mortar mix which is stirred only with water;

- from all starting materials including water in the central production. It is in the form of a wet mortar mixture which is transported to another place of use.

Mechanical mixing is usually done in a concrete mixer. A small amount of mixing water is placed in the mixer followed by sand, cement and then lime or another binder. More water is then slowly added to create a thick creamy mortar. Each batch should be thoroughly mixed for three minutes to ensure that a uniform consistency is obtained. Hand mixing should be done in a clean wheelbarrow or on a mixing board to avoid contamination. The raw materials should be combined and mixed until a uniform colour is achieved. Water is then slowly added with the continuous turning of the mix until a thick creamy mortar is obtained [9].

According to the usage, mortars are distinguished especially as masonry mortar, rendering and plastering mortar. Moreover, mortars are used for laying floor tiles and wall tiles, for grouting and the production of ceramic parts. The important thing is using this mortar such as the contact mortar, grouts and renovation plaster for the surface treatment of building structures [6].

Mortar is defined as a paste obtained by adding water to a mixture of fine aggregates and binding material, e.g. clay, gypsum, lime or cement or a combination of more than one of them. The material so formed is capable of setting and hardening.

The materials for mortar are as follows:

- binder - most commonly, mortar is based on the cement and lime. For the preparation of mortars both these binders can be used alone or in combination. Today the use of mix hydraulic binder based on Portland cement clinker (Portland cement CEM I, Portland slag cement CEM II/A, B-S and special cements) is more frequent. For the reconstruction of architectural monuments lime and gypsum or their combination are used.
- filler - sand is the natural fine aggregate component of the mortar. Various types of sand ranging from coarse or sharp sand to fine sand are used depending on the binding environment or use. Sand used for mortar should be free from impurities that will impair its functionality. Inorganic aggregates based on wastes (granulated blast slag, fly ash) and plant fibres are used in mortar, too.

- water - for the mortar production it has to be harmless.

- additives - such as plasticizing additives are added in a small amount from the amount of the binder before stirring or during mixing the mortar in order to modify the properties of mortars.

- admixtures - fine inorganic materials used to improve the properties of the mortar or to achieve special properties. Pigments (inorganic or organic) added to colour the mortar should not exceed $10 \%$ of the weight of cement in the mix and should be thoroughly mixed with the other materials prior to the addition of water [6], [9].

\section{Types of mortars}

Types of mortars have been defined by J. Výborný [6]. Industrially produced mortars are classified according to the standards:

- STN EN 998-2. Specification for mortar for masonry. Part 2: Masonry mortar [10].

- STN EN 998-1. Specification for mortar for masonry. Part 1: Rendering and plastering mortar [11].

Standard STN EN 998-2 applies to masonry mortar designated for storing, jointing and grouting on masonry walls, pillars and partitions, loaded and unloaded masonry structure, face and plastered masonry. Standard STN EN 998-2 classifies masonry mortar:

- according to conception:

- designed masonry mortar,

- prescribed masonry mortar;

- according to the mode of manufacture:

$\circ$ factory-made masonry mortar,

- semi-finished masonry mortar,

o site-made masonry mortar;

- according to the properties and/or use of:

$\circ$ general purpose masonry mortar $(\mathrm{G})$,

- lightweight masonry mortar (L),

- masonry mortar for thin joints (T) [10].

Requirements for the internal and external mortar are given in the standard STN EN 998-1. Rendering and plastering mortars are divided to the types of rendering or plastering mortar:

- according to conception:

- designed rendering or plastering mortar,

- prescribed rendering or plastering mortar;

- according to the mode of manufacture:

○ factory-made rendering or plastering mortar,

- semi-finished rendering or plastering mortar,

o site-made rendering or plastering mortar;

- according to the properties and/or use of:

- general purpose rendering or plastering mortar (GP), 
$\circ \quad$ lightweight rendering and plastering mortar (LW),

○ coloured rendering or plastering mortar (CR),

one-coat rendering mortar for external use (OC),

○ thermal insulating mortar $(\mathrm{T})$,

- renovation mortar $(\mathrm{R})$ [11].

Clay mortar is made of a binder and fillers, wherein the function of binder is fulfilled only by clay and the function of fillers is performed by sand in different fractions. Mortar does not contain any hydraulic binder. To prevent the emergence of undesirable shrinkage cracks, fibrous fillers such as animal hair, shives, hemp hurds and other plant and wood fibres are added to the clay mortar.

Thin film plasters are also referred to as modern plaster for final surface treatment of facades. Thin film plasters are distinct from classical plasters which are applied at a thickness of only a few millimetres. According to the type of binder used, they are split into mineral (lime-cement), acrylic, silicone and silicate thin film plasters.

Renovation plasters are intended for surface treatment of wet and salinization masonry. This plaster is also used for additional waterproofing of buildings that do not have functional waterproofing which forms a finish of salinization masonry.

Thermal insulation mortar prevents the formation of thermal bridges in the mortar joints between bricks and increases the thermal resistance of masonry. Thermal plaster can be used in particular to a temperature less exposed parts of buildings, for the insulation of doors, windows, and staircases. Higher heat resistance of masonry can be achieved using thermal insulation plaster on both sides of masonry.

Mortar for tiles is used in the laying of tiles and has also the function of a balancing layer.

Bonding mortar is used as a cementitious mortar for mounting parts or to fill the space between parts (grouts) [6].

\section{Plaster base installation}

For plastering, there must be a continuous surface to which the plaster can be applied and to which it will cling-the plaster base. A continuous concrete or masonry surface may serve as a base without further treatment.

Two-coat plaster work consists of a single base coat (4-5 $\mathrm{mm}$ ) and a finish coat (to $20 \mathrm{~mm}$ ). Three-coat plaster work consists of two base coats (the scratch coat and the brown coat) and a finish coat $(2-2.5 \mathrm{~mm})$. Finish coat proportions vary according to whether the surface is to be finished with a trowel or with a float. The trowel ensures a smooth finish; the float produces a textured finish.

Plastering requires the use of a number of tools, some specialized, including trowels, hawk, float, straight and feather edges, darby, scarifier, and plastering machines. Fig. 1 presents some examples of tools for plastering.

Interior plaster can be finished by troweling, floating, or spraying. Troweling makes a smooth finish; floating or spraying makes a finish of a desired surface texture.

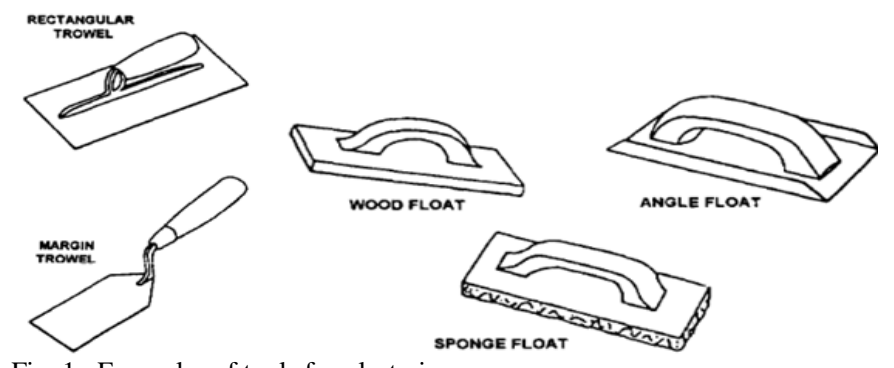

Fig. 1. Examples of tools for plastering.

Some special interior-finish textures are obtained by methods other than or in addition to floating. A few of these are listed below:

- stippled - after the finish coat has been applied, additional plaster is daubed over the surface with a stippling brush or roller.

- sponge - by pressing a sponge against the surface of the finish coat, you get a very soft, irregular texture.

- dash - the dash texture is obtained by throwing plaster onto the surface from a brush. It produces a fairly coarse finish that can be modified by brushing the plaster with water before it sets.

- travertine - the plaster is jabbed at random with a whisk broom, wire brush, or other tool that will form a dimpled surface. As the plaster begins to set, it is troweled intermittently to form a pattern of rough and smooth areas.

- peggle - a rough finish, called peggle, is obtained by throwing small pebbles or crushed stone against a newly plastered surface. If necessary, a trowel is used to press the stones lightly into the plaster [12].

\section{CELlulOSE FIBRES}

In the recent years, much more attention has been paid to sustainable, green and environmental friendly materials for various applications [13].

Lignocellulose-based fibres or particles are the most widely used as biodegradable reinforcing elements or partial replacement of binder or filler for composite materials. In the last years, the utilisation of lignocellulosic materials to process novel composites has attracted a growing interest. Such a success is explained by their low-cost and their environmentally friendly character [3]. Indeed, important industries, such as automotive, building and packaging, have focused their attention on the development of new materials filled with natural fibres or powdered particles. In addition to the above-mentioned advantages, these materials possess interesting mechanical and physical properties [14], which, however, vary according to their botanical origin. In fact, lignocellulosic fibres or particles are available mainly from wood, but several local annual plants and agricultural crops as well as industrial residues can also be considered as potential sources of raw materials [3]. During the last decade, several composites based on lignocellulosic materials from worldwide annual plants, such as Cannabis sativa, kenaf, eucalyptus, rice straw, bagasse and cotton have been studied [14]. 
Microstructure of wood pulp fibres and recycled waste paper fibres using scanning electron microscope (SEM) is shown in Figs. 2 and 3.

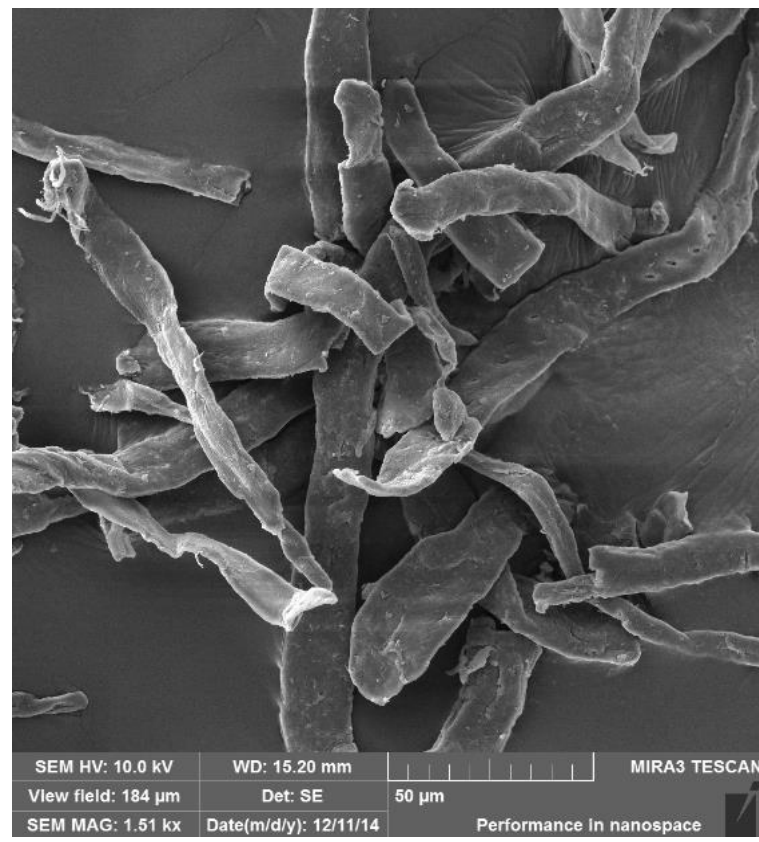

Fig. 2. Microstructure of wood pulp fibres using SEM $(1500 \mu \mathrm{m})$.

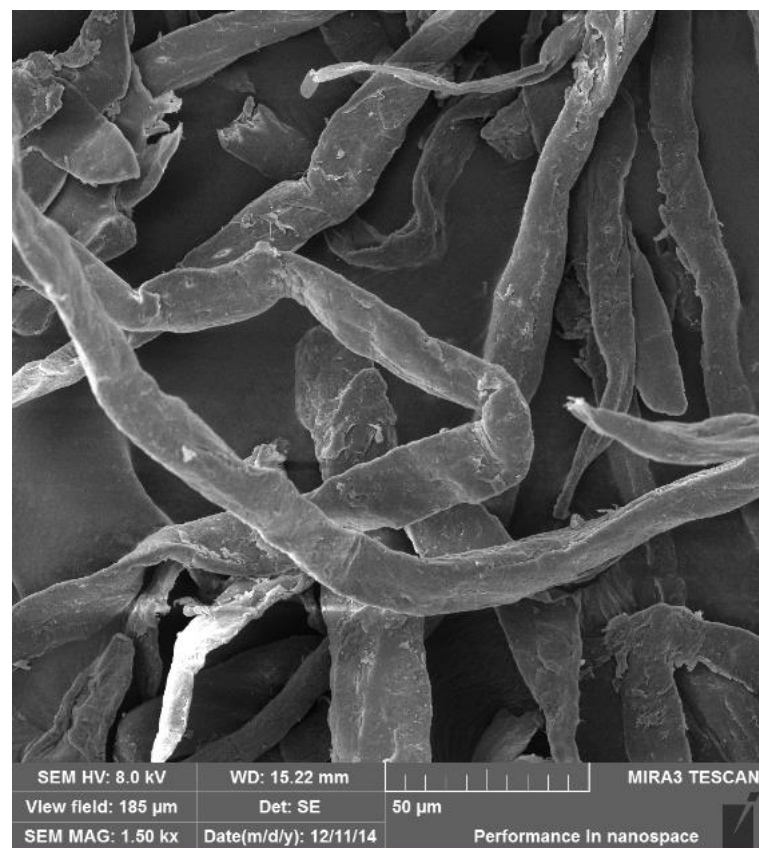

Fig. 3. Microstructure of recycled waste paper fibres using SEM $(1500 \mu \mathrm{m})$.

Among the possible alternatives, the development of pulp and paper industries and bio-composites using the recycled paper is currently in the centre of attention [15], [16]. It is an excellent alternative waste material to substitute wood because it is plentiful, widespread, and easily available. In addition to abundance and renewability, utilization of the recycled paper has advantages for the economy and environment [17]. When paper waste is used as secondary fibres for papermaking, it requires extensive treatment for deinking, cleaning, and refining. Unlike papermaking process, when the recycled paper is used for the manufacture of cement composites, it does not require extensive preparation [18].

The primary advantages of using lignocellulosic fibres as additives in cement are their low density, low cost, nonabrasive nature, high filling levels possible, low energy consumption, and wide variety of fibres available throughout the world. Two main disadvantages of using lignocellulosic fibres in cement are high moisture absorption of the fibres and composites and low compatibility between fibres and cement [19]. Lignocellulosic fibres are mainly constituted of carbohydrates such as cellulose, hemicellulose and extractives (including tannins, phenols, lignins, etc.). Extensive research, however, shows that using chemical admixtures under controlled compaction and temperature conditions can lead to a wide range of fibre reinforced cement composites with excellent durability properties and with very satisfactory levels of long-term performance under internal and external exposure conditions [15], [16], [18].

\section{A. Use of cellulose fibres in cement based composites}

Wood pulp fibres constitute the major portion of the natural fibres used in cement-based materials. Pulp fibre-cement composites are gaining popularity because of the advantages associated with the fibres - including widespread resource availability, high fibre tensile strength, high fibre modulus of elasticity, relatively low cost, and the well-developed technology to extract the fibres - as well as advantages associated with fibre-cement composites themselves [20].

In the study [21], recycled fibres obtained from waste packing boxes and papers were used for the preparation of cement composites. Nine mixtures with different proportions of fibres $(2-16 \%$ by weight), cement, recycled clay brick aggregates and water were prepared. Testing of physical properties of 28 days hardened specimens showed that there is an obvious relationship between fibre content and thermal conductivity. Values of thermal conductivity and bulk density decreased when quantity of fibres in the composite increased. This behaviour was also reported by authors using different kinds of vegetable fibres [22], [23]. Similar trends in dependence on fibre content were observed at testing of mechanical characteristics of hardened composites. Flexural strength increased in the range of fibre content up to $4 \%$ and higher portion of fibres led to a progressive decrease in the value of fibre content. Relationship between compressive strength and fibre content demonstrates a decreasing trend. The recycled fibres from post-consumer waste have offered advantages of waste reduction and resources protection if this material can be used more for construction and insulation purposes. However, more investigations are needed in order to reduce content of cement and sand by using renewable raw materials or secondary raw materials.

In the following study [1], the influence of four different types of re-pulped waste paper (newspaper, office paper, carton paper and mixed papers) and their portion (20\%, $40 \%$, $60 \%$ and $80 \%$ by mass of cement) on key properties of the composite were investigated. Mechanical and thermal properties of hardened composite specimens were tested after 28 days. The variations of compressive strength with different types and contents of re-pulped waste paper are shown in Fig. 4. 


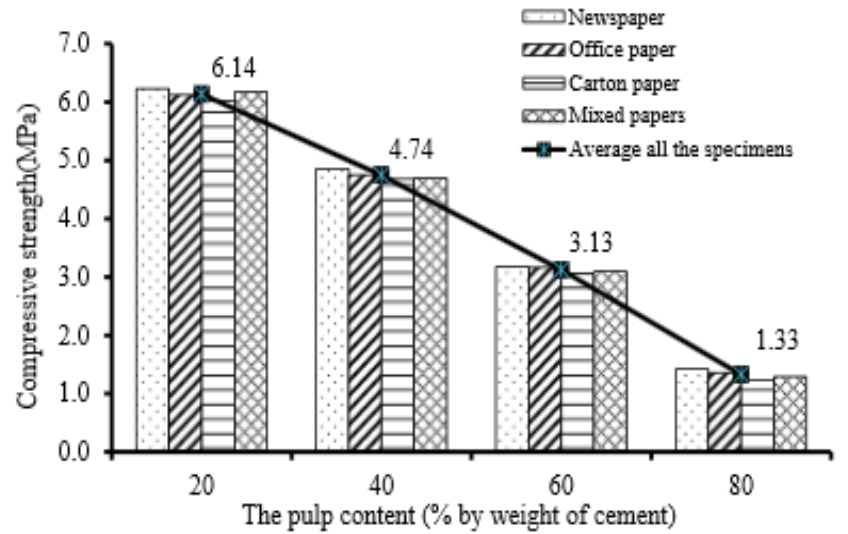

Fig. 4. Compressive strength of the prepared composites using re-pulped waste paper.

As is shown in Fig. 4, the values of the compressive strength decreased with increasing the pulp content. This is due to the fact that increasing the content of cellulose fibre pulp yields a lot of void in the specimen. Therefore, this leads to a lower compressive strength and bulk density. The values of thermal conductivity and bulk density of cement composites decreased with increasing quantity of the pulp content.

In the study [19], recycled newsprint paper collected by recycling company as the lignocellulosic raw material was used. The reinforcing effect of the recycled newsprint paper in cement boards has been investigated. The experimental design consisted of Portland cement and two variable factors, namely, recycled newsprint paper and calcium chloride $\left(\mathrm{CaCl}_{2}\right)$. Boards were manufactured using fibre/cement ratios of 10:90, 15:85 and $20: 80$ by weight and $3 \%$ and $5 \% \quad \mathrm{CaCl}_{2}$ as accelerator. Testing of the mechanical (modulus of rupture and modulus of elasticity) and physical properties of the boards showed that addition of $\mathrm{CaCl}_{2}$ tends to enhance both the mechanical and physical properties of the boards. All properties of the boards were improved when $\mathrm{CaCl}_{2}$ content increased from $3 \%$ to $5 \%$. The rupture and elasticity modulus of the boards decreased with an increase in the recycled newsprint paper content, and the maximum values were obtained at recycled newsprint paper loading of $10 \%$ (Fig.5).

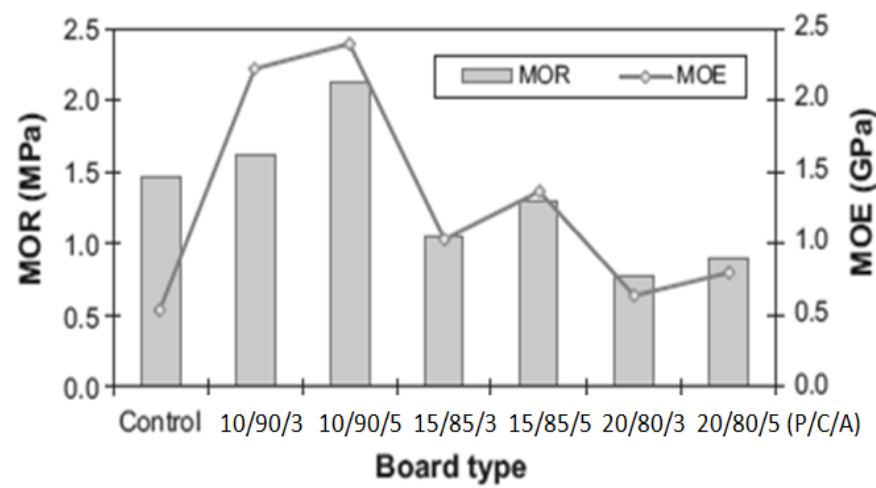

Fig. 5. Modulus of rupture (MOR) and modulus of elasticity (MOE) of various board types (P/C/A - paper fibres / cement / additive).

The results also showed that as the fibre content increased, significant increase in water absorption was observed and swelling of fibres occurred. Increasing recycled newsprint paper fibre content from $10 \%$ to $20 \%$ reduced both the mechanical and physical properties considerably. The optimum conditions were obtained when the recycled newsprint paper and $\mathrm{CaCl}_{2}$ contents were $10 \%$ and $5 \%$, respectively.

\section{CONCLUSION}

The use of waste fibres as reinforcement in cement composites has enormous potential in building material production. The composites based on the optimised mixture of cellulosic fibres from the recycled paper, binder and admixtures present an acceptable behaviour in comparison with cement composites produced with virgin wood cellulose fibres. The availability of fibrous wastes also supports their potential utilization through sustainable methods of production of building components.

The task of plaster is not only to improve the appearance of the building, but also to protect it against the consequences of weather conditions, fluctuations in temperature, humidity and air pollution. Natural fibres have been used to reinforce cement based products in various applications around the world. These included materials are obtained from different parts of plants (for example fibres of jute, flax, hemp, sisal, banana, wood pulp). Due to their good mechanical properties, the tensile strength, flexibility and crack resistance of the resulting material can be improved. In this paper, fundamental knowledge on mortar/plaster and on the use of cellulose fibres in composite is presented. Study of physical and mechanical properties will be conducted in further research.

\section{ACKNOWLEDGMENT}

The authors are grateful to the Slovak Grant Agency for financial support of the project VEGA 1/0277/15.

\section{REFERENCES}

[1] V. Sangrutsamee, P. Srichandr and N. Poolthong, "Re-pulped Waste Paper-Based Composite Building Materials with Low Thermal Conductivity," Journal of Asian Architecture and Building Engineering, vol. 11, pp. 147-151, May 2012.

[2] S. R. Karade, "Cement-bonded composites from lignocellulosic wastes," Journal of Construction and Building Materials, vol. 24, pp. 1323-1330, Aug. 2010. http://dx.doi.org/10.1016/j.conbuildmat.2010.02.003

[3] R. Khiari, Z. Marrakchi, M. N. Belgacem, E. Mauret and F. Mhenni, "New lignocellulosic fibres-reinforced composite materials: A stepforward in the valorisation of the Posidonia oceanic balls," Composites Science and Technology, vol. 71, pp. 1867-1872, Sep. 2011. http://dx.doi.org/10.1016/j.compscitech.2011.08.022

[4] B. J. Mohr, H. Nanko and K. E. Kurtis, "Durability of kraft pulp fibercement composites to wet/dry cycling," Cement \& Concrete

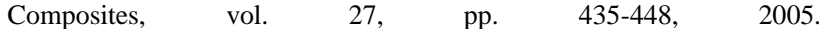
http://dx.doi.org/10.1016/j.cemconcomp.2004.07.006

[5] E. Dianova, "Puzzolanas and their reactivity in lime mortars," Masaryk University, Brno, Czech, 2010.

[6] J. Vyborny, Mortars. Building Materials. Bratislava, SVK: Jaga group, 2005, pp. 199-213.

[7] A. Palomo, M. T. Blanco-Varela, S. Martinez-Ramirez, F. Puertas and C. Fortes, "Historic Mortars: Characterization and Durability. New Tendencies for Research," Eduardo Torroja Institute, CSIC, Madrid, Spain. [Online]. Available: http: www.arcchip.cz/w09/w09_palomo.pdf. [Accessed: Nov. 10, 2014].

[8] F. Silva, R. D. T. Filho, Sisal Fiber Reinforcement of Durable Thin Walled Structures - A New Perspective: CBM-CI International 
Workshop, 2008, Karachi, Pakistan. Pakistan: NED University of Engineering and Technology Karachi, 2008.

[9] Building Technology Demystified, "Composition and uses of lime and mortar". [Online]. Available: https://buildingtechnology.wordpress. com/2011/01/18/composition-and-uses-of-lime-and-mortar/. [Accessed Nov. 10, 2014].

[10] STN EN 998 - 2. (2011). Specification for mortar for masonry. Part 2: Masonry mortar.

[11] STN EN 998 - 1. (2011). Specification for mortar for masonry. Part 1: Rendering and plastering mortar.

[12] "Plastering, Stuccoing, and Ceramic Tile". [Online]. Available: http://www.constructionknowledge.net/public_domain_documents/Div_ 9_Finishes/Partial\%20pdfs/Plaster_section_NAVEDTRA_14044.pdf. [Accessed: Nov. 10, 2014].

[13] H. P. S. Abdul Khalil, Y. Davoudpour, Md.Nazrul Islam, A. Mustapha, K. Susesh, R. Dungani, M. Jawaid, "Production and modification of nanofibrillated cellulose using various mechanical processes: A review," Carbohydrate Polymers, vol. 99, pp. 649-665, 2014. http://dx.doi.org/10.1016/j.carbpol.2013.08.069

[14] A. K. Bledzki, J. Gassan, "Composite reinforced with cellulose based fibers," Prog. Polym. Sci., vol. 24, pp. 221-274, 1999. http://dx.doi.org/10.1016/S0079-6700(98)00018-5

[15] Z. Si-Yang, P. Ji-Cheng, Z. Xin-Lu, H. Hui-Ren, H. Yi-Mei, "Fiber modification of OCC pulp with laccase and natural mediator system", Advanced Material Research, vol. 113-116, pp.1801-1805, 2010.

[16] Y. M. Wei and B. Tomita, "Effects of five additives materials on mechanical and dimensional properties of wood cement-bonded particle boards," Journal of Wood Science, vol. 47, pp. 437-444, 2001 http://dx.doi.org/10.1007/BF00767895
[17] E. Afra, H. Resalati, J. A. Olson and Pourtahmasi, "Assessment of OCC pulp fractionation using fibre passage ratio model," Appita Journal, vol. 62, pp. 350-354, 2009.

[18] A. Ashori, T. Tabarsa and I. Valizadeh, "Fiber reinforced cement boards made from recycled newsprint paper," Material Science and Engineering, vol. A 528, pp. 7801-7804, 2011.

[19] B. J. Mohr, N. H. El-Ashkar and K. E. Kurtis, Fiber-Cement Composites for Housing Construction: State-of-the-Art review: NSF Housing Research, 2004, Orlando, FL. 2004.

[20] R.D. Toledo Filho, K. Ghavami, K. Scrivener and G. L. England, "Durability of Alkali-sensitive Sisal and Coconut Fibres in Cement Mortar Composites," Cement \& Concrete Composites, vol. 22, pp. 127143, 2000. http://dx.doi.org/10.1016/S0958-9465(99)00039-6

[21] M. Bentchikou, A. Guidoum, K. Scrivener, K. Silhadi and S. Hanini, "Effect of recycled cellulose fibres on the properties of lightweight cement composite matrix," Construction and Building Materials, vol. 34, pp. 451-456, 2012. http://dx.doi.org/10.1016/j.conbuildmat.2012.02.097

[22] M. Bentchikou, A. Guidoum, K. Scrivener, K. Silhadi and S. Hanini, Effect of cellulose fibres on the thermal and mechanical properties of cement paste: Conference on the use of recycled materials in building and structures, 2004, Barcelona, Spain. 2004.

[23] D. Guerin, V. Morin, D. Chaussy and J. L. Auriault, Thermal conductivity of hand sheets, paper and model coating layers: Transaction $12^{\text {th }}$ fundamental research symposium, 2001, Oxford, UK. 2001. 